Article

\title{
More or Less Political: Findings on a Central Feature of Local Engagement for Refugees in Germany
}

\author{
Verena Schmid *, Adalbert Evers and Georg Mildenberger \\ Centre for social Innovation and Investment, Max-Weber Institute, Heidelberg University, 69115 Heidelberg, Germany; \\ E-Mails: verena.schmid@csi.uni-heidelberg.de (V.S.), adalbert.evers@csi.uni-heidelberg.de (A.E.), \\ georg.mildenberger@csi.uni-heidelberg.de (G.M.)
}

* Corresponding author

Submitted: 20 December 2018 | Accepted: 3 May 2019 | Published: 27 June 2019

\begin{abstract}
The article is based on research in the region of Heidelberg - the city itself and two small municipalities nearby. It addresses three dimensions of local support movements for refugees: (1) the varying bundles of motives among those engaged, (2) the diversity of organizations concerned and (3) their interaction with the local political administration. A focal point of the study concerns features and processes that give actions and organizations a more or less political character. Our results reveal that, especially among newly engaged helpers and activists, political and apolitical motives coexist. Many people and their local organizations take positions in the country-wide controversial political debates on refugees, but for their practical action on location, moral concerns clearly prevail. Processes of politicization and depoliticization of refugee support largely depend on the ways and degrees to which nationwide political controversies and local developments intermesh. Politicization may take place due to controversies that call for more than a moral attitude, have an impact and build up at the local level. However, resistance to supportive action, be it by changing discourses or the persistence of traditional administrative routines, may also cause depoliticization, where volunteers and initiatives restrict themselves to acting as mere helpers that bring some human touch into an environment that longs to return to normality.
\end{abstract}

\section{Keywords}

civil society; governance; local policy; migration; political engagement; refugee aid; volunteering

Issue

This article is part of the issue "The European Refugee Controversy: Civil Solidarity, Cultural Imaginaries and Political Change", edited by Gert Verschraegen (University of Antwerp, Belgium) and Robin Vandevoordt (University of Oxford, UK/University of Antwerp, Belgium).

(C) 2019 by the authors; licensee Cogitatio (Lisbon, Portugal). This article is licensed under a Creative Commons Attribution 4.0 International License (CC BY).

\section{Introduction}

In Germany, there was no other development in recent decades in which the engagement of the civil society became more important than in the handling of the refugee question. In September 2015, 15\% of the German population aged 16 and above were somehow engaged on behalf of refugees (Birkenfeld et al., 2017, p. 201); every second genuine refugee relief organization was founded in 2015 (Priemer, Krimmer, \& Labigne, 2017, p. 39). The media and public debates acknowledged the enormous size of this support movement and its impact as a sign for an open minded "welcome culture". Yet, by portraying the engagement as that of an enormous number of voluntary "helpers", questions about the diversity of motives, practices, organizational forms and relations with given institutional frameworks often stayed covered or secondary. This article will give a more differentiated picture. And on this basis, it will focus on the question, to what degree this movement has as well a political dimension that is going beyond its impact as a contestation of human concern.

In this perspective the research presented in this article has taken up four issues: (1) Why did citizens become 
engaged? (2) What impact did the design and variety of the organizational landscape have on the resulting activities? (3) What does civil society participation in local governance look like when it comes to practical handling and political decision making on refugee issues in cities and municipalities? And finally, (4) what has been the impact of a changing environment and a turn in the dominant political discourse from an overall positive attitude toward integrating refugees to the present focus on making borders close and safe?

The findings to be presented are based on a study that was part of a larger project network (www.reallaborasyl.de) that also explored several other questions such as pathways of refugees into the labor market. As such, the research had two limits. First, its focus was on the local dimension of a development, movement and conflict that concerns society and politics in Germany as a whole. Second, it was limited to the cities Heidelberg, Sinsheim and Wiesloch, where-unlike in other cities and regions, especially in the new German states-a sharp counter movement of enraged citizens that rejected refugees did not exist locally.

The differentiated picture of the central features of local engagement for refugees in Germany to be presented here to a broader international public provides the basis for putting a widely held public notion to a test, often endorsed by government officials: the welcome and active support for refugees have been a sign of commitment and practical solidarity, organizing considerable additional resources that made it easier for local administrations, organizations and policy makers to cope with the sudden challenge of locally integrating refugees and asylum seekers. Our findings support a different, more complicated diagnosis than the simple picture of "a good government supported by good citizens". With respect to the four questions above we found:

(1) A heterogeneity of motives and actions, ranging from simple humanitarian support to critical political action; attitudes may be both "political" and "apolitical";

(2) Developments at the organizational level, that show a coexistence of traditional associations and new initiatives and organizational forms; they attracted volunteers and activists partly in similar, partly in different ways, some of them more, others less open to voicing concerns that go beyond practical help;

(3) Institutional forms on the level of governance and networking services, that differ from the traditional corporatist culture of inter-sectoral cooperation and from a fairly standardized service provision; the tension between old and new forms may be a politicizing issue to the degree it is brought to the surface;

(4) A development over time in this heterogeneous field, where so far tendencies that politicize and others that depoliticize support movements exist simultaneously.

Our research and the article based on it intertwine information that gives a broad understanding of refugee support on local levels and the discussion of a focal pointthe more or less political character of this engagement. In a nutshell, "politicizing" tendencies are those by which conflicts between different actors and their respective goals, such as between local governments and local initiatives, become highly public issues, for example, regarding the impact of integrative as compared to repressive measures or the degree new forms of integrative support and cooperation call for changing services and governance. "Depoliticizing" tendencies, then, are those by which such potentially controversial topics are subdued by a discourse that portrays civic engagement in support of refugees as a purely humanitarian, largely technical and organizational affair, taking the existing political and administrative frameworks largely as given. In the following (Section 2), the conceptual background, the levels of observation and the empirical methods of the study are outlined. The next sections present the results of our analysis concerning the variety of forms and types of engagement (Section 3), the diverse organizational forms (Section 4), and the way new kinds of more or less institutionalized cross-sector cooperation and governance have been established (Section 5). In Section 6, we once again take up and discuss the findings in sections 3 to 5 with respect to the present and future, possibly more or less political meaning and impact of local support movements for refugees in Germany. The conclusions (Section 7) highlight questions from our study on civic engagement for refugees that may be likewise important in other policy fields and for the overall future status and political influence of civic movements and organizations in Germany.

\section{Conceptual Background, Level of Observation and Method of the Study}

The conceptual background of our study, focusing on the role of civic engagement, forms of its organization and the place this holds in the (local) governance system, is marked by two convictions shared by some approaches but not all (for the debate on such points in civil society research see Evers \& von Essen, 2019):

- We think that civic engagement is an umbrella term for a wide field of differing forms of engagement that range from voluntary work, practices such as personal help and supportive services to civic action and diverse forms of participation in politics and from forms that support a prevailing consensus to others that are special interest based, innovative and controversial (for such an approach see Evers \& von Essen, 2019; Zweiter Engagementbericht für die Bundesregierung, 2017, p. 68). 
- We assume that the development and role of specific actions and organizations can be best understood through relational approaches-focusing on the ways changing environments, conditions and discourses alter the image of a specific initiative and engagement (Griggs \& Howarth, 2014; Schmidt, 2010); for example, a concern with refugees may thus turn from being seen as a widely acclaimed humanitarian cause into a highly controversial political topic. Whether the narrative of a movement of "apolitical helpers" will stay as an uncontested "myth" (Fleischmann \& Steinhilper, 2017) or whether kind of "subversive" qualities of the humanitarian concerns that guide many of those engaged will become effective (Vandevoordt \& Verschraegen, 2019) depends very much from developments over time and a context wherein discourses and politics matter much. Local actors, movements and networks are very much dependent, neither victims nor masters of such developments.

It was from this background that our project explored the motivations and the means of engagement of individuals around the refugee issue, the trends and innovations involved, and how informal and formal civil society actors interact with each other and with policy makers, especially municipal actors, but also with actors from the private sector, and what significance this has with respect to conventional forms and understandings of local cooperation and governance.

This task led to three levels of observation in our research. We looked firstly at the actions and motives and forms of the actors and organizations involved in refugee aid. Secondly, we looked at the organizational forms, the already existing and the newly emerging ones' in local civil society that dealt with issues of refugee aid. Thirdly, we looked at the networking and its links with local governance, both traditional and new forums for cross-sector mediation and cooperation.

As we began our research, the field of refugee aid and the actors involved in it were still in flux. Accordingly, an ethnographical approach was chosen that was able to reflect the unstructured nature and diversity of the situation (Hammersley \& Atkinson, 2009, pp. 3-5). This approach was embedded in a practice-oriented transdisciplinary setting, emphasizing the dialogue with individual and collective actors. In practice this means that for two years participant observations took place in the field and were recorded in a field diary. The subjects of the observations were networking events, citywide events and internal meetings of organizations in Heidelberg, Sinsheim and Wiesloch. At about 20 of such meetings we conducted, implying observations and supplementary discussions. The number of participants varied from five to over 20, depending on the event. In addition, 14 qualitative individual and group interviews between three quarters of an hour and two hours were realized, with a variety of volunteers and representatives of key organizations in the field, focusing on attitudes and experiences in relation to the three levels of observation mentioned above. The individual interviews were conducted mainly with representatives of organizations to learn more about their ideas, structures and activities. Institutionally independent volunteers were also interviewed individually. The group interviews were conducted with regular volunteers of the organizations to better understand the dynamics and negotiation processes within the organizations. All interviews were recorded and transcribed. Furthermore, we did a document analysis of websites, newspaper articles, flyers and similar items related to individual organizations and to the general process of coping with the refugee challenge in the three cities. Our "dialogic" approach sought to avoid both judgements from an academic distance and a partisan view.

Several organizations, selected according to their position in the field, were described in more detail by case studies, compared with each other and placed in the local context. Organizations were explored that formed part of the mainstream of refugee support as well as others with different and unique profiles. The collected data were analyzed using grounded theory methodology (Glaser \& Strauss, 1998). To generate relevant categories, the three steps of open coding, axial coding and selective coding were used, supported by the program Atlas.ti. Of the eight key categories that were generated, three are presented in this article. In between the analysis phases, we continued going back to the field in order to collect additional data. This iterative research process took place until a theoretical saturation was reached. For the reconstruction of the individual cases as well as the case comparison, a procedure of qualitative case contrasting was used according to the sequential method (Kelle \& Kluge, 2010, p. 79).

\section{The Diversity of Types and Forms of Engagement}

Many of the findings on engagement in refugee aid in Heidelberg, Sinsheim and Wiesloch confirmed what is in principle known from debates on forms and motives of volunteering and civic action in general and in the field of pro-refugee engagement in particular (Karakayali \& Kleist, 2015, 2016; Linnert \& Berg, 2016). As described in the discussion about changing attitudes and ways of showing commitment among the volunteers of today, there are both a growing desire to pursue individual motives such as finding personal fulfilment and demands for more flexible time management, with an openness toward casual and temporary engagement (Peglow, 2002, p. 27). Among our respondents, the majority became involved in this field for the first time. They found their respective engagement through calls for support in the newspapers or through their own inquiries in city offices or on the internet. Mostly their main motive was to somehow help in what was perceived as a situation 
of "crisis". The means of participation were very different, ranging from individual projects and events to provide personalized support by taking care of one or a limited number of refugees, to time-consuming paraprofessional engagement by setting up and finally organizing and leading a support association. On the one hand, the volunteers sought to make the work compatible with their own limits, preferences and timetables, on the other hand, they also accepted the importance of reliability and of being a role model in the usually fairly structured everyday lives of the refugees:

Activities were organized by day's schedules about who comes for help at what times; from the very beginning we have tried to demonstrate reliability, making fixed dates and times for our tasks. (Interview Baumann)

A mix of rather classic, altruistic and self-related motives were depicted by the phrases coded under the category motivation. The altruistic side can be illustrated by phrases such as "co-shaping society on a micro-level", "help as a civic duty" or "being challenged by humanitarian emergency". When it comes to self-related motives, phrases such as "motivation through positive experiences", "motivation: meaningful pastime" or "motivation: getting to know foreign cultures" were often mentioned.

Beyond these basically known variations of balancing altruism and self-interest, three observations deserve special attention.

First, we found a difference between two types of engagement for refugees. The first type is more about giving the recipients a kind of support in which personal contact with the individual is secondary. Organizations that give legal support may have a highly fluctuating clientele, and those that give advice are motivated by a generalized concern with international support and solidarity. At the other end of the spectrum are those settings and initiatives in which the helpers built up a personal commitment to the people they supported over a longer time period; some kind of personal relationship, trust and solidarity that emerge along with that help plays much more of a role here. In such case-by-case relationships, people do not fight for a particular concept of refugee rights in the first place, but rather try to create the best possible situation for individual refugees for which they have taken personal responsibility. This kind of relationship promotes a morally grounded engagement based on values such as compassion and hospitality. In the German debate, "welcome culture" was an oft-used notion for this bundle of such motions and attitudes.

Second, we found that to a considerable extent the actions of the volunteers are determined by the dynamics of personal relationships and not primarily by their conformity with an organization, its purposes and status. We saw that helpers and volunteers build and use personal connections to refugees, other helpers and in- stitutional partners to find or negotiate solutions outside of the official structures, rules and proceedings (e.g., exemptions, special agreements, etc.). Good relations with other persons or groups are important for this type of refugee aid. Such informal communications outside or underneath official levels and sectoral and institutional routines may work both as lubricants and as corrosive instruments. Via this pragmatic approach that seeks visible results in the face of administrations and rules that cannot be changed, personal networks are used to soften the rigidity of institutionalized rules. A form of engagement and cooperation takes shape at the local level in which the dynamics of interpersonal relationships are of primary importance rather than pre-defined functional provisions and task assignments of the respective organizations.

Such different kinds of intermeshing and balancing of a personal and a generalized responsibility have much to do with our third basic observation on the degrees and logics of politicizing or depoliticizing engagement around the refugee challenge. The engagement that we found is often both "political" and "apolitical".

There is a broad debate about the political dimension of civic engagement. Much of it is reflected in the differentiation between voluntary action and civic activism. While the former is mostly seen as a kind of practical action with mostly loose and often weak ties to the world of politics, the latter is defined by the degree citizens participate in, negotiate with or protest against state rules and politics. In this perspective civic action is more political than voluntary work since it is more entangled with politics. However, another perspective opens up once a distinction is made between "politics" and "the political", defining the latter according to what becomes openly controversial in public (for this and other determinations of the political, see Bröckling \& Feustel, 2012; Mouffe, 2005). Accordingly, politicization means that (formerly) barely debated, almost natural facts and circumstances turn into contested topics of public debates and decisions. For example, there are circumstances in which engagement in providing refugee support can be widely accepted as an almost natural human gesture. However, the discourses and public controversies over multiculturalism and on the limits of open societies as they have arisen in the last decade (see, e.g., Betts \& Collier, 2017) have revealed a process by which what is to be done and changed in the name of "good" and "human" attitudes has become highly disputed and therefore an increasingly "politicized" topic. People's engagement may become politicized in that way. By the same token, depoliticizing dynamics might also exist, resulting, for example, from a discourse getting widely acceptance that favors closure over openness: if citizens that engage on behalf of refugees (must) accept this discourse's restrictions, they have to resort to doing what is possible, i.e., "sane" and "constructive" in such a narrowed space.

In conversations and interviews with people engaged in refugee support we found that very often the two 
principles coexisted within the individuals, held in some distance to each other. On the one hand, people's engagement was related to political judgements and positions with regard to the controversies on the refugee question that are argued out in "big politics" by proponents and adversaries of the concept and feasibility of an "open society". The influence of this orientation was particularly strong in the first type of engagement, in which volunteers fight explicitly in the name of political principles such as international solidarity and legal status. On the other hand, the practical action on the local level was mostly morally grounded; it is a kind of humanitarian obligation to help the people that one finds next door in a refugee camp. Their opinions about the national-level controversies on ways to go about solving the refugee question are merely a bit of background that might be linked to but do not directly determine the local set of individual goals and actions. Therefore, national politics and local humanitarian action were often found to be two different spheres. This division evokes the reflections on the "politics of community" in Habits of the Heart (2008), where "politics is a matter of making operative the moral consensus of the community" (Bellah, Madsen, Sullivan, Swidler, \& Tipton, 2008, p. 200). As long as politics is seen as a matter of controversies on the larger stage, a morally grounded humanitarian action at the neighborhood level can be taken nonetheless. Still, one's own local actions can be linked with "big politics" insofar as they help to strengthen one's own moral choice.

Things may change, however, the very moment a task or rule that comes from big politics has a concrete effect in one's own community, be it by forcing asylum seekers into camps segregated from the local community or be it by deciding to use some of the city's ever scarce public housing resources for refugees. We come back to this point later on in Section 6.

\section{The Diversity of Organizational Forms}

Supporting refugees locally must be seen as a kind of movement that fundamentally affects the organizational landscape across sectors although to different degrees. It is not just a matter of a delineated subsector of civil society organizations.

An Internet search and a newspaper analysis of the local newspaper Rhein-Neckar-Zeitung in the period from January to December 2016 revealed a picture of the diverse organizational landscape of refugee aid in Heidelberg, Sinsheim and Wiesloch. This included not only civil society but also state, municipal, and private sector entities and not only specifically refugee aid organizations but also those that had expanded their field of activity, opening up their services for refugees. It was not possible to track down all organizations, as there are organizations that do not have an internet presence and do not report on their actions in the local press. What became evident was the great variety of organizations that deal with refugee challenges, both pre-existing and newly founded ones. Unfortunately, however, the exploration did not allow us to draw conclusions concerning the impact and share of support for refugee compared to other purposes.

In Heidelberg, 137 civil society, 22 private sector and 32 municipal actors were active in the period analyzed. In Wiesloch, 62 civil society, 10 private sector and $22 \mathrm{mu}$ nicipal actors were identified and for Sinsheim, 32 civil society, 4 private sector and 18 municipal actors (see Figure 1).

History and courses of institutionalization matter for understanding this picture. Within the organizational landscape of civil society organizations as it developed over more than a century (see Evers, 2019), there are large, well-established organizations dating back to the late 19th century, linked with the Catholic and Protestant churches and the labor movement. Then there are organizations that took shape alongside the "new social movements" of the 1970s, such as those that stand for international solidarity and human rights (e.g., Pro Asyl), and other groups dating back to former episodes of refugee influx in the 1990s, such as the Arbeitskreis Asyl (Working Group on Asylum Issues) in Heidelberg. Finally, as elsewhere, there are many completely new groups dealing with the refugee challenge such as the Kontakt-

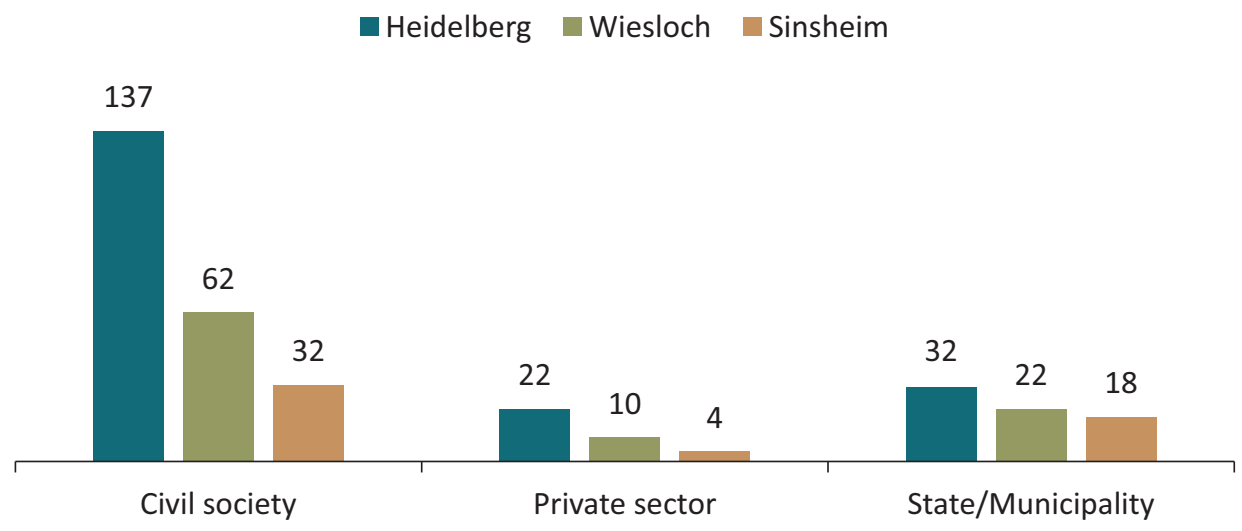

Figure 1. Numbers of organizations in Heidelberg, Wiesloch and Sinsheim. 
werkstatt (Contact Workshop). Unlike the old and traditional organizations, many of the more recent associations, projects and actions are concerned with advocacy, legal advice, and the organization of workshops and debates. Their focus is not on support that is intertwined with personal relationships but rather on the fate and the legal position of a target group.

In summary, our analysis showed that movements to support refugees are very heterogeneous, not only in terms of organizational structure but also in terms of goals and action. We found older and newer organizations in which the emphasis is on a more or less personalized help and support and others that focus on more controversial political tasks such as advocacy for the rights of refugees and asylum seekers, on organizing public attention and debates, influencing the climate of opinion, and on taking the role of watchdogs with respect to administration and politics. Perhaps the people engaged in such activities would see themselves as "civic activists" rather than as "voluntary workers".

\section{Cooperation and Governance across Sectors and Policy Fields: The Role of Networks and Intermediary Forums}

Most of the organizations engaged on a largely voluntary base in refugee support have learned to build contacts with different groups, institutions and subject areas, in particular in order to build a flexible support network that links services from different fields, ranging from food and shelter to education, work and housing. Networking can involve cross-sector cooperation between administrative offices and policy makers, voluntary organizations and initiatives, potential employers, and the business sector. Arrangements have to be negotiated that allow for flexible adaptation to changing needs and circumstances. No wonder then that local platforms for cooperation and mediation play a major role in all three of our cities, both for joint action of local civil society organizations and for negotiating crosssector arrangements.

Those forums and networks have very different shapes. In Sinsheim, a central network is coordinated by the local public authorities, while in Heidelberg a civil society organization was founded in order to take on this task. Quite often there are roundtable meetings of local networks, where people from different contexts and sectors usually meet on an equal footing. The main themes and aims of such meetings rarely relate to general questions, such as the operation of the whole refugee and asylum network, but rather focus on finding solutions to individual cases and problems and attempting to get every potentially helpful actor involved. Participating there is foremost about being part of a problem-solving process, where everyone contributes what resources he or she has to offer. This is where working groups can be established and projects and solutions for individual cases can be developed across traditional demarcation lines between policy fields and administrative structures. This means that the development of new forms of personalized support, centered on the whole person, and not just a coordination of specific traditional problem sections, stands in the center (Evers \& Klie, 2018, p. 529).

However, such new ways of cooperation, a result of the local support movements as they took shape from the summer of 2015 onwards, shed some light on the earlier established structures. Germany's welfare regime is characterized by a welfare mix in which non-profit organizations play an important role as service providers and partners of the public authorities, which act as financing and regulating bodies. Over decades a strong culture of local corporatism (Thränhardt, 1981), a system of negotiation and joint planning, has developed in which the political administration and the most important traditional welfare associations take part. This system however proves to be inappropriate when it comes to integrating both new networked forms of personalized support and new approaches of self-organization that go beyond the traditional forms of negotiating tasks and contracts in committees dominated by firmly institutionalized conventional welfare associations and their ideas about proper services.

There is yet another point where we found that these new cooperation structures challenge the known style of corporatist governance. Unlike in the traditional corporatist settings, where citizens' participation was to be guaranteed by the representatives of welfare associations, the new roundtables and meetings are open to individual participation and a broader variety of more or less formalized organizations with new people engaged in often not yet routinized kinds of responsibilities. Of those engaged in refugee support, $42 \%$ were involved outside the existing organizational structures, and 5\% even completely alone (Karakayali \& Kleist, 2015, p. 25). No wonder then that the new collaboration platforms allow the loosely structured volunteers to learn about projects, needs for action and different requirements, so that they can spontaneously engage with their ideas.

Often however, the established welfare organizations were overstrained by the role of networking and rearranging their intermediary position between state and local politics. New platforms and roundtables for coordination were founded. In this article we cannot sketch the variations of the networking and intermediation processes and attempts that occurred in Wiesloch, Sinsheim and Heidelberg. But in Heidelberg, for example, an established refugee aid organization took over the role of network development and moderation:

In the beginning, about 2014 to 2015, we tried to pass information in areas where one runs the risk to do things wrong, areas where you must have experience and knowledge and we told volunteers: "Okay, look at this and that institution, try to get information from them and in case you want to start up with a project, why not do it together and by an agreement 
with them". So, you see, we have tried to guide the activities a bit. (Interview Bravo)

As the quote indicates, networking and mediating were first and foremost about giving orientation and avoiding damage. However, this also resulted in longer-term cooperation, which further strengthened the position of the organization.

It should be emphasized that the new platforms for decision-making on local refugee work and the establishment of new forms of support in which a personcentered networking and cooperation plays a central role have only a short history. These are shaky institutions and there are no blueprints for effective work and further development of such intersectoral governance hubs. For any community that does not simply want to return to traditional corporatist forms, it remains a major challenge to negotiate such new ways of operating and communicating and to strengthen the respective platforms and ways of networking.

With respect to the question of politicization and depoliticization this altogether means that there is a latent conflict, so far managed and held down by the very pragmatic practices of many of the new actors. Their new forms of personalized support coexist but are not at ease with traditional administrative routines. And acting besides the traditional forms of cooperative local governance the new platforms and round tables that emerge have so far, an unclear and unsecure status. Will they silently vanish, get coopted or explicitly challenge the traditional institutions and practices?

\section{Towards a Politicization of the Local Field? The Development over Time}

In order to understand where, and in what ways, approaches to politicization emerge in the course of these developments, it is important to track the dynamics of local engagement and changes in the range of activities pursued.

The first phase of the refugee aid in mid-2015 was characterized by a broad spontaneous engagement to provide shelter-at railway stations, sports halls and similar temporary accommodation facilities-and material support with respect to food, clothing and health issues. The volunteers did not wait until the existing structures became active but took the given circumstances in a local context as a trigger for their engagement. This also resulted in the emergence of quite a number of new organizations and support networks.

Being aware that government officials had difficulties to act quickly, the volunteers' focus was on measures to address the humanitarian emergency at that time. The activities of the volunteers took place around initial reception, care, accommodation, collection campaigns and donations. In addition, there were already first offers of services such as language courses, assistance in dealing with authorities, help with translation, etc.
A second phase of engagement was accompanied by a decline in the number of new refugees arriving. Many of the spontaneous initiatives that emerged in the first phase went through a process of professionalization. An actor reports:

And the cooperation with the volunteer network had been good right from the beginning, but it has become better all the time because, I think, by more work experience among those engaged a kind of increasing professionalization has built up. Possibly some people withdrew that did not engage so well which meant that those which stayed and engaged themselves really with heart and soul, doing high quality work; the retreat of some improved the cooperation between those that remained. (Interview Bravo)

The challenges turned from ad hoc help to societal integration, with facets ranging from questions of obtaining housing to working opportunities, establishing conditions for childcare and school attendance, and obtaining rights for monetary support. In all these areas, however, there exist rules, administrative and professional practices and routines that organizations and volunteers would have to deal with. They began to stabilize their structures and to specialize in various fields of activity. The kind of cooperation with the administrative system became then more differentiated and complicatedaway from "managing chaos" to securing the livelihood of the refugees and following procedures in line with given rules and regulations and all the bureaucratic steps accompanying them. Networking and exchanging experiences about possibilities to cope with government officials became increasingly important. Cooperation with local authorities became more diverse and more detailed and changed in character. The activities became increasingly determined by the specifications and working methods of the various administrative offices. Cooperation moved away from direct contact with officials on provisional solutions towards cross-sector arrangements where the impact of administrative and professional traditions dominate over the more personal, flexible and communicative attempts to find ways of coping that are suited for a new clientele.

Charged with all the experience of over two and a half years of engagement for refugees in an ever less supportive policy environment and in front of administrations that push for old and new rules set by them, a new phase emerges. It is no longer about finding fast solutions for individual cases; the volunteers now encounter structural problems and questions of fundamental changes in the rules and practices of social administrations.

Many actors in the municipal institutions themselves have become aware of this, and it has also become their concern. However, so far just parts of the organizations of those engaged are prepared to take up the negative experiences and to voice their concerns in public. Quite often fatigue arises when short-term successes do not 
materialize, and when bureaucratic hurdles and lengthy processes wear out the volunteers. For example, when volunteers wanted to act as advocates for the refugees in complicated clarifications about rights and rules, this was quite often made impossible due to data privacy prescriptions. The attempt to develop "networked help for the whole person" then became increasingly difficult or even unachievable.

Experiences with the system and bureaucratic procedures, by which the specific aspects of a "case" are negotiated separately by health, social, educational, housing and labor market services and that are not constructed for support of especially "weak" clients such as refugees (Bogumil, Hafner, \& Kastilan, 2017), can have quite different effects. They can cause frustration but also contradictions and conflicts that politicize once they become topics of public concern.

To be confronted with the alternative, to restrict and shape one's own activity according to the seemingly quite erratic rules of the respective professions and offices, or to become ineffective can become a central starting point for processes of politicization among volunteers. What is finally left for helpers in such a system? Why do their "partners" in administrations and politics not listen to their ideas or consider their practices and suggestions of doing it a different way?

One of the important factors in this respect is the role taken by various civil society organizations. There is a basic tendency among the large, established welfare organizations to act as service providers rather than as public advocates for policy change. In confronting the refugee challenge, their umbrella organizations may complain about scarce resources for integration and more emphasis on getting refugees back out of the country; but we did not find much voice or action from their side on the local level concerning these topics. Here, they were seemingly occupied with providing those services contracted by the public authorities. The advocacy organizations for the rights of refugees and asylum seekers and their local representatives have few resources and apparently little impact. The same can be said about the newer organizations that offer various kind of innovative services and support; they are often dependent on the financing that comes from special government programs on national, federal and local levels. In general, there is little opportunity to give the critical experiences of volunteers and activists an organizational voice.

At the same time however, problems experienced locally tend to become a political issue at a central, national level and vice versa.

An example for ways from "below" to "above" is a query from the parliamentary group of the liberal party regarding on the continued absence of an option to give financial support to persons with a tolerance or residence permit when they take up studies or training. Another example is the debate on recurring cases in which asylum seekers that had found an employer and a decent job as well as other means of integration, were forced to leave the country. Why not offer them a simplified path towards permission to stay? Here the abstract and general political question about a more or less "open society" takes on very concrete form and content. Moral questions and political alternatives intertwine. Lacking hope for better and more cooperative answers from the given administrative, professional and political system, issues concerning the need to change such frameworks become highly public topics.

A positive politicization of questions of dealing with refugees can also take the opposite route from "above" to "below"; "big politics" come into the local and find a stage there. This is reflected in Heidelberg, for example, with the case of a family who was deported. Many people accused the city of not taking advantage of its freedom of action to keep the family in place. They called for local political parties to take a stand and put the issue on the city's political agenda. Even beyond the local context, they tried to draw attention to the case by writing an open letter to the Baden-Württemberg Minister of Science and the Baden-Württemberg parliamentary group and the State Association of the Green Party. Here an engagement was shown that is "political" insofar as different moral viewpoints connect with concrete alternatives of action.

In addition, local confrontations with right-wing populist developments are expanding. For example, a local training program for volunteers picks up the topic in two workshops: "Pitting oneself against right-wing slogans" and "Highly dangerous: How the silence of the Middle strengthens the Right". Also, the volunteers in training are asked to think about what is needed to confront xenophobia.

And you have to watch out that Germany does not undergo a strong shift to the right. That means that one has to stop the kind of political statements made increasingly now. This kind of hostility against strangers. That should be obvious. I think as well in the public reports, the media something should change. Putting it in more concrete terms, forums that report on the other side should get more room. (Interview Zimmermann)

It is obvious that shifting public discourses and politics, e.g., the increasing concern of many politicians with tighter borders of "open societies", more control and repression and less imaginative programs and resources for intercultural settings, change the conditions for local support movements. Their political significance may be reduced, and for many it may seem unavoidable to accept the role of subordinate helpers. But some may well become more political by struggling for a larger mandate. This is the case especially where it becomes apparent that good and sustainable support for refugees on the local level calls for changes of traditional rules and attitudes among bureaucracies and a kind of engagement that questions such restrictions. By the same token, 
refugee support can become more political where nationwide contentious political debates are not the mere distant background for local humanitarian actions but where both dimensions intertwine. One's position in the debate should then prove to be more or less legitimate according to the actions taken and vice versa. Such a statement about the more or less political character of local support movements for refugees and asylum seekers does not deny basic tendencies once described by Eliasoph (1998) about much volunteer initiative "avoiding politics", tending to keep politics at a distance. But our findings point to the fact that how it plays out may vary considerably according to contexts and the ways leaders, activists and volunteers find to deal with them. Borders between political and apolitical engagement can blur and shift-not only according to "circumstances" but also as a result of decisions of the people engaged and their respective organizations.

\section{Conclusions}

Civil society engagement is particularly pronounced in the field of refugee policy. How does it look on local levels in Germany and in which respect and to what degree does it have a political character? We have analyzed this central question with respect to three dimensions of the support movement, i.e., motives, organizational forms and the relations with the institutional framework and moreover with an eye on the dynamics over time so far:

- Actions and motives: There are different types and forms of engagement at the local level. Quite often among helpers and activists, we found various kinds of intermeshing and balancing a personal and a generalized commitment for refugees as well as the co-existence of a kind of humanitarian obligation to help and a political standpoint in the overall controversy regarding refugee politics.

- Organizational form: These kinds of more or less political engagement go along with a wide variety of forms of organization, ranging from traditional, established entities to newer and brandnew groups, covering activities that span from the prevailing practical and often personalized help and support to advocacy and campaigning. Organizations act fairly different when it comes to take up controversial points about policies and politics of dealing with refugees.

- Networking and local governance: For most of these tasks, networking and cooperation on the local level are important, across both policy fields and sectors. New personalized forms of networked support, local platforms for cooperation and intermediation that differ from the traditional forms of local corporatism have taken shape. So far, the political challenge of coming to new forms of servicegiving and to different institutional forms of cooperation is however mostly held at bay.
The findings concerning the diversity, dynamics and more or less political character of civic engagement in the field of local refugee support, seem to us as relevant beyond local settings and the special area of dealing with the refugee challenge. With an eye on that they may be reformulated:

- Volunteers as "helpers": Today we are experiencing a strong tendency, not only in the area of engagement for refugees, to perceive volunteers as mere "helpers". How can a new understanding of roles be developed that includes activities beyond being a "helper" who operates within prescribed rules, dominant institutions and assigned tasks? Should we not acknowledge the diversity of kinds of engagement, including dimensions such as innovative social support schemes, advocacy, campaigning and more voice in joint strategies for integration and inclusion? This is an eminent political question, a matter of controversies between those that want to upgrade the role of civic engagement and those who prefer to hold it on the level of an add-up to the given system.

- New organizational landscapes: The ofteninvoked new engagement-an attitude that mixes self-directed motives with solidarity, selfdetermination, and attachment in a variety of ways - is displayed in new forms of organizing and community building that include a voice for those engaged in its forms and developments. At the same time, space for an engagement that is sensitive to people's preferences can also be maintained by traditional organizations with stable frameworks that work as a relief; they offer potential helpers a choice of different kinds and degrees of engagement. How significant and politicized can volunteering become in both cases and settings? How much acknowledgement will be reached by new, often lesser and differently organized forms of an engagement, that is often not only about help but as well about advocacy and resistance?

- Civic organizations as parts of a new type of governance: Local refugee policy reflects a desire for new forms of cooperative local governance, with all their challenges and opportunities. As they gain visibility in the field of refugee support, can platforms and networks become sustainable in the face of established, traditional forms of corporatist mediation and trends towards privatization of public tasks handed over to agencies and subcontractors? This as well would be a serious political question, once it comes to the surface and gets a matter of public debate.

What about the future? Will refugee support and related volunteering and civic action become more or less political? One might speculate in both directions. We have highlighted two developments that are important in this 
respect: one, the conflicts and frustrations that arise out of a mere bureaucratic handling of support and integration issues and, two, the interplay between controversial refugee politics at the national level and what seems reasonable and feasible on the local level. The often frustrating experiences with administrative and professional rigidities may reduce the space and meaning of volunteering since it would be difficult at present for these negative experiences to become the basis for a broader public push for reforms that might make established welfare services more responsive. Furthermore, there is a longing on various sides to return to "normality", and this is unfavorable for political debates over mainstreaming innovative concepts and initiatives. But there is also a positive interplay between local and central action that might strengthen the political dimensions of engagement in this field. On the central level, Germany experienced in late 2018 the largest demonstrations since decades (with more than 240,000 participants in Berlin) in support of refugees and against the positions of the radical right in this respect. This was only possible due to the significant support of the activated initiatives, organizations and scenes as they have built up locally in urban and rural regions over time. To the extent that people stand on the national level for an open society that recognizes limits and borders but must not close itself off, this can encourage local initiatives with their search and demands for solutions that are viable and innovative, offering helpers and activists horizons that go beyond filling gaps by way of a bit of human touch.

\section{Acknowledgments}

This research was part of the Real-World Laboratory Asylum in Heidelberg therefore we would like to thank the Ministry of Science, Research and the Arts in BadenWürttemberg for the project funding. We also acknowledge financial support by Deutsche Forschungsgemeinschaft within the funding program Open Access Publishing, by the Baden-Württemberg Ministry of Science, Research and the Arts and by Ruprecht-Karls-Universität Heidelberg.

\section{Conflict of Interests}

The authors declare no conflict of interests.

\section{References}

Bellah, R. N., Madsen, R., Sullivan, W. M., Swidler, A., \& Tipton, S. M. (2008). Habits of the heart. Individualism and commitment in American life. Berkeley, CA: University of California Press.

Betts, A., \& Collier, P. (2017). Refuge: Rethinking refugee policy in a changing world. New York, NY: Penguin Random House.

Birkenfeld, D., Dehne, P., Evers, A., Geißel, B., Hüther, M., Klie, T., . . . Wegner, M. (2017). Zweiter Bericht über die Entwicklung des bürgerschaftlichen Engagements in der Bundesrepublik Deutschland. Schwerpunktthema: "Demografischer Wandel und bürgerschaftliches Engagement. Der Beitrag des Engagements zur lokalen Entwicklung" [Second report on the development of civic engagement in the Federal Republic of Germany. Main topic: "Demographic change and civic engagement and its contribution to local development"]. Freiburg im Breisgau: Federal Ministry for Family Affairs, Senior Citizens, Women and Youth (BMFSFJ).

Bogumil, J., Hafner, J., \& Kastilan, A. (2017). Verwaltungshandeln in der Flüchtlingspolitik: Vollzugsprobleme und Optimierungsvorschläge für den Bereich der kommunalen Integration [How administration handle refugee politics. Suggestions for the area of local integration]. Verwaltungsarchiv, 108(4), 467-488. https://doi.org/10.1515/verwarch-2017-0401

Bröckling, U., \& Feustel, R. (2012). Einleitung. Das Politische denken [Introduction. Conveying the political]. In U. Bröckling \& R. Feustel (Eds.), Das Politische denken. Zeitgenössische Positionen [Conveying the political. Contemporary positions] (pp. 7-18). Bielefeld: transcript Verlag.

Eliasoph, N. (1998). Avoiding politics: How Americans produce apathy in everyday life. Cambridge: Cambridge University Press.

Evers, A. (2019). Diversity and coherence: Historical layers of current civic engagement in Germany. Voluntas, 30(1), 41-53.

Evers, A., \& Klie, A. W. (2018). Flüchtlinge und Engagement [Refugees and civic engagement]. In T. Klie \& A. W. Klie (Eds.), Engagement und Zivilgesellschaft. Expertisen und Debatten zum Zweiten Engagementbericht [Engagement and civil society. Expertise and debates on the Second Report on civic engagement] (pp. 513-546). Wiesbaden: Springer Verlag für Sozialwissenschaften.

Evers, A., \& von Essen, J. (2019). Volunteering and civic action: Boundaries blurring, boundaries redrawn. Voluntas, 30(1), 1-14.

Fleischmann, L., \& Steinhilper, E. (2017). The myth of apolitical volunteering for refugees: German welcome culture and a new dispositiv of helping. Social Inclusion, 5(3), 17-27.

Glaser, B. G., \& Strauss, A. (1998). Grounded theory. Strategien qualitativer Forschung [Strategies of qualitative research]. Bern: Huber Verlag.

Griggs, St., \& Howarth, D. (2014). Post-structuralism, social movements and citizen politics. In $\mathrm{H}$. van der Heijden (Ed.), Handbook of political citizenship and social movements (pp. 279-307). Cheltenham: Edward Elgar.

Hammersley, M., \& Atkinson, P. (2009). Ethnography. Principles in practice. London: Routledge.

Karakayali, S., \& Kleist, O. (2015). EFA-Studie. Strukturen und Motive der ehrenamtlichen Flüchtlingsarbeit (EFA) in Deutschland [EFA-Study. Structures and 
motives of voluntary support for refugees in Germany]. Berlin: Berlin Institute for Integration and Migration Research (BIM), Humboldt University of Berlin.

Karakayali, S., \& Kleist, O. (2016). EFA-Studie 2. Strukturen und Motive der ehrenamtlichen Flüchtlingsarbeit (EFA) in Deutschland [EFA-Study 2. Structures and motives of voluntary support for refugees in Germany]. Berlin: Berlin Institute for Integration and Migration Research (BIM), Humboldt University of Berlin.

Kelle, U., \& Kluge, S. (2010). Vom Einzelfall zum Typus. Fallvergleich und Fallkontrastierung in der qualitativen Sozialforschung (2nd ed.) [From single case to type. Case comparison and case contrasting in qualitative social research]. Wiesbaden: VS Verlag für Sozialwissenschaften.

Linnert, J., \& Berg, T. (2016). Freiwilligenarbeit mit Geflüchteten. Forschungsstand zum freiwilligen Engagement mit Geflüchteten unter Aspekten gesellschaftlicher Teilhabe und politischer Bildung (Working Paper). Berlin: Des Projekts Perspektive Teilhabe.

Mouffe, C. (2005). On the political. New York, NY: Routledge.

Peglow, M. (2002). Das neue Ehrenamt. Erwartungen und Konsequenzen für die soziale Arbeit [The new mode of volunteering. Expectations and consequences for social work]. Marburg: Tectum-Der Wissenschaft.

Priemer, J., Krimmer, H., \& Labigne, A. (2017). ZiviZ-
Survey 2017. Vielfalt verstehen [Understanding diversity]. Ziviz. Retrieved from https://www.ziviz.info/ ziviz-survey-2017

Schmidt, V. (2010). Taking ideas and discourse seriously: Explaining change through discursive institutionalism as the fourth 'new institutionalism'. European Political Science Review, 2(1), 1-25.

Thränhardt, D. (1981). Kommunaler Korporatismus. Deutsche Traditionen und moderne Tendenzen [Municipal corporatism. Traditions in Germany and modern tendencies]. In D. Thränhardt \& H. Uppendahl (Eds.), Alternativen lokaler Demokratie [Alternatives for local democracy]. Königstein: Hain.

Vandevoordt, R., \& Verschraegen, G. (2019). Subversive humanitarianism and its challenges: Notes on the political ambiguities of civil refugee support. In M. Feischmidt, L. Pries, \& C. Cantat (Eds.), Refugee protection and civil society in Europe (pp. 101-128). Basingstoke: Palgrave Macmillan.

Zweiter Engagementbericht für die Bundesregierung. (2017). Demografischer Wandel und bürgerschaftliches Engagement: Der Beitrag des Engagements zur lokalen Entwicklung [Demographic change and civic engagement and its contribution to local development]. Freiburg im Breisgau: Federal Ministry for Family Affairs, Senior Citizens, Women and Youth (BMFSFJ). Retrieved from https://www.bmfsfj.de/ blob/115624/d6da5ce2163c59600f48a7a5d360a3 b2/2-engagementbericht-und-stellungnahme-brdata.pdf

\section{About the Authors}

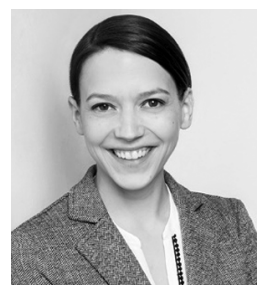

Verena Schmid is a scholarship holder of the Friedrich-Ebert-Stiftung and works at the Centre for Social Investment of University of Heidelberg. Her research focus lies on the issues of civil society and civic engagement. Furthermore, questions on the field of knowledge sociology and the sociology of organizations are included in her scientific work. Her doctoral thesis sheds light on how memories of the past construct the presence of the volunteers in the refugee aid.

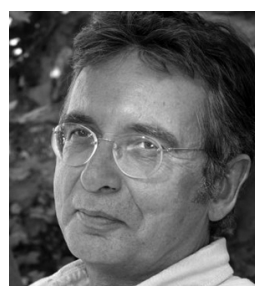

Adalbert Evers is a Political Scientist, doing research and teaching on social policy and social services, civil society, third sector organizations, social innovation and governance. He is presently affiliated to the Ersta Sköndal University College, Stockholm and works as a Senior Fellow at the Centre for Social Investment (CSI), Max-Weber-Institute for Sociology, Heidelberg University.

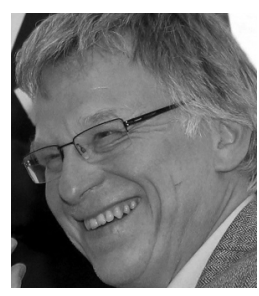

Georg Mildenberger manages the research department of the Centre for Social Investment of University of Heidelberg. He has been working at CSI since 2007 and has been leader of different project teams working on social innovation in a European context. He holds a doctoral degree from Darmstadt University, and a master's degree in philosophy and political science from Tuebingen University. 